\title{
Non-migrating Diurnal Tides Generated with Planetary Waves in the Mesosphere
}

H. G. Mayr ${ }^{1}$, J. G. Mengel ${ }^{2}$, E. R Talaat ${ }^{3}$, H. S. Porter ${ }^{4}$, and K. L. Chan ${ }^{4}$

${ }^{1}$ Goddard Space Flight Center, Greenbelt, MD, 20771

${ }^{2}$ Science Systems \& Applications, Inc., Lanham, MD

${ }^{3}$ Applied Physic Laboratory, Johns Hopkins University, Laurel, MD

${ }^{4}$ Furman University, Greenville, SC

${ }^{5}$ Hong Kong University of Science and Technology, Hong Kong, China

Submitted

to

Geophysical Research Letters

May, 2003 
Abstract: We report here the results from a modeling study with our Numerical Spectral Model (NSM) that extends from the ground into thermosphere. The NSM incorporates Hines' Doppler Spread Parameterization for small-scale gravity waves (GWs) and describes the major dynamical features of the atmosphere, including the wave driven equatorial oscillations (QBO and $\mathrm{SAO}$ ), and the seasonal variations of tides and planetary waves. Accounting solely for the solar migrating tidal excitation sources, the NSM generates through dynamical interactions also nonmigrating tides in the mesosphere that have amplitudes comparable to those observed. The model produces the diurnal (and semidiurnal) oscillations of the zonal mean $(\mathrm{m}=0)$, and eastward and westward propagating tides for zonal wave numbers $m=1$ to 4 . To identify the mechanism of excitation for these tides, a numerical experiment is performed. The NSM is run without the heat source for the zonal-mean circulation and temperature variation, and the amplitudes of the resulting nonmigrating tides are then negligibly small. This leads to the conclusion that the planetary waves, which normally are excited in the NSM by instabilities but are suppressed in this case, generate the nonmigrating tides through nonlinear interactions with the migrating tides.

\section{Introduction}

Measurements from the ground (e.g., Avery et al., 1989; Manson et al., 1989; Vincent et al., 1989) and with the Upper Atmosphere Research Satellite (UARS) spacecraft (Hays et al., 1994; McLandress et al., 1996; Burrage et al., 1995a, b) have shown that the diurnal tides in the mesosphere and lower thermosphere exhibit large seasonal variations. It has been proposed that some of the variability is due to modulation by planetary waves (e.g., Teitelbaum and Vial, 1991; Forbes; 1995, Fritts, 1995a, b). The amplitude of the fundamental diurnal tide exhibits large maxima during equinox, which have been attributed to postulated variations in eddy viscosity (e.g., Geller et al., 1997; Yudin et al., 1997), and to variations in eddy viscosity associated with gravity wave interaction (Akmaev, 2001a). 
In the Numerical Spectral Model (NSM) discussed here, the seasonal variations of the fundamental diurnal tide were attributed also to gravity wave (GW) momentum deposition and filtering by the mean zonal circulation (Mayr et al., 1998, 2001a). The seasonal variations of the semidiurnal tide were shown to be affected significantly by nonlinear interactions with the diurnal tide through gravity wave filtering (Mayr et al., 2001a). Planetary waves generated internally by instabilities and GW forcing (Mayr et al., 2001b) were shown to produce large amplitude modulations of the diurnal and semidiurnal tides.

The above observations and modeling results refer mainly to the dominant westward migrating tides. In the upper mesosphere, however, the nonmigrating tides also contribute significantly to the observed temperature and wind fields. Based on an analysis of UARS High Resolution Doppler Imager (HRDI) measurements over a period of four years, Talaat and Lieberman (1999) observed in the diurnal (24 hour) tide above $80 \mathrm{~km}$ large amplitudes in the zonal wave number $\mathrm{m}=0$ and eastward propagating components in $m=1-3$ as well. Examination of the deduced phase structure of stratospheric and mesospheric observations generally suggests that the nonmigrating diurnal tides are propagating up from below (Lieberman, 1991; Talaat and Lieberman, 1999). However, their excitation mechanisms are not yet fully understood. Forcing of the non-migrating tides due to solar insolation of tropospheric water vapor and stratospheric ozone (the main source for the migrating diurnal tides), and latent heat release, as well as convective or sensible heating cannot produce the amplitudes or seasonal variation observed in the mesosphere (e.g., Miyahara et al., 1993; Ekanyake et al., 1997; Hagan et al., 1997). As an alternative means to generate nonmigrating diurnal tides, preferential longitudinal dissipation of the migrating tide has been suggested (Khattatov et al., 1996). Waltersheid et al. (1986) suggested that gravity waves interacting with migrating tides could generate nonmigrating components. Teitelbaum and Vial $(1989,1991)$ proposed that non-linear interactions between migrating tides and planetary waves could generate the non-migrating components. Miyahara et al. (1999) suggested that nonlinear interaction between waves could produce the nonmigrating tides in their model. Based on simulations with the TIME-GCM model, Hagan and Roble (2001) recently suggested that non-linear interactions between the migrating diurnal tide 
and stationary $m=1$ planetary waves can produce measurable non-migrating tides in the upper mesosphere.

Investigating further the above discussed mechanism, we present a study with the NSM by performing two numerical experiments: one with planetary wave generation, the other without. The results conclusively demonstrate that non-migrating tides, having amplitudes comparable to those observed in the mesosphere, are generated in the model through nonlinear interactions between planetary waves and migrating tides.

\section{Numerical Spectral Model}

The Numerical Spectral Model (NSM) extends from the Earth' surface up into the thermosphere were homogeneous boundary conditions apply, and its design and applications have been discussed in the literature (e.g., Chan et al., 1994; Mengel, et al., 1995; Mayr et al., 1998, 2001a). The model is driven in the zonal mean $(m=0)$ by the solar heating due to UV radiation in the mesosphere and stratosphere taken from Strobel (1978), and by EUV radiation in the thermosphere. The radiative loss is described in terms of Newtonian cooling, for which the parameterization of Zhu (1989) was recently adopted. The tides are driven exclusively by the thermal migrating excitation sources in the troposphere and stratosphere (Forbes and Garret, 1978). Nonmigrating tides associated with convection or topography are not accounted for. The planetary waves are generated only through instabilities that arise in the mean zonal $(\mathrm{m}=0)$ temperature and wind fields; no planetary wave source of any kind is prescribed in the model.

An integral part of the NSM is that it incorporates the Doppler Spread Parameterization (DSP) for small-scale gravity waves (GWs) (Hines, 1997a, b) that deals with a spectrum of waves interacting with each other to produce Doppler spreading. This in turn affects the interaction of the waves with the background flow, which is important for the dynamics of the middle atmosphere. The DSP has also been applied successfully in a variety of other global-scale models (e.g., Akmaev, 2001b; McLandress, 1997; Mancini et al., 1997) and has been discussed extensively in the literature.

The $3 \mathrm{D}$ version of the NSM discussed here differs from the earlier version in that tropospheric heating in the zonal mean $(m=0)$ is applied to reproduce qualitatively the observed zonal jets near the tropopause and the accompanying latitudinal temperature 
variations. We earlier applied such a heat source in our 2D version of the NSM to study its affect on the wave driven equatorial oscillations (QBO, SAO). In 3D, this additional heat source also generates planetary waves, excited again by instabilities, which propagate into the stratosphere and mesosphere under the influence of GW interactions.

\section{Model Results}

The above-discussed model was run to cover several years, and the results reveal persistent features in the seasonal and latitudinal variations of the migrating as well as nonmigrating tides. In this short paper, pars pro toto, we restrict the discussion to the fundamental diurnal tide to describe a particular mechanism that can generate relatively large nonmigrating tides in the mesosphere.

In Figure 1, we present the computed meridional winds for zonal wave numbers $\mathrm{m}=$ 0 to 2 with a period of 1 day ( 24 hours), delineating the eastward and westward propagating components. The tidal oscillations were extracted from a period of two months (24 to 36 months) at the beginning of the 3 rd computer year near solstice with the Sun in the southern hemisphere. For a running window of 4 days, a Fourier analysis was carried out, and the largest amplitudes are plotted versus latitude and altitude from 70 to $100 \mathrm{~km}$. The lowest $50 \%$ of the contours are suppressed, and the maximum wind velocities are recorded.

The computed wind amplitudes in Figure 1 show, as expected, that the westward propagating component (dashed) dominates for wave number $m=1$ (with a maximum value of $81 \mathrm{~m} / \mathrm{s}$ ), and it reveals also significant differences between the northern winter and southern summer hemispheres. By comparison, the eastward propagating component ( $16 \mathrm{~m} / \mathrm{s}$ maximum) is much smaller and does not show up in the displayed contours. We emphasize, that this eastward propagating tide is not generated directly by a specified tidal excitation source. And the same is also true for all the other tidal components in Figure 1, including the one for $\mathrm{m}=0(36 \mathrm{~m} / \mathrm{s}$ maximum $)$ that does not propagate and the one for $\mathrm{m}=2$ with $15 \mathrm{~m} / \mathrm{s}$ maximum that propagates westward. The nonmigrating tides for the wave number $m=3$ and 4 (not shown) have maximum amplitudes around $10 \mathrm{~m} / \mathrm{s}$. 
For the zonal wind amplitudes (somewhat smaller and not shown), the relative differences between wave numbers are similar to those for the meridional winds. With the horizontal Coriolis force vanishing at the equator, however, the computed zonal winds for $\mathrm{m}=0$ essentially vanish there. (The vertical component of the Coriolis force is accounted for in the NSM).

The model results reported here can be related to the analysis of UARS measurements by Talaat and Lieberman (1999). As discussed in that paper, satellite sampling did not permit the unambiguous separation of the diurnal tides for $\mathrm{m}=0$ and the one for $\mathrm{m}=2$ propagating westward. The inferred phase progression of the $m=0$ tide was seen as evidence for aliasing of the $\mathrm{m}=2$ tide. From the NSM, the meridional winds for $\mathrm{m}=0$ (Figure 1a) are symmetric about the equator (shown is only the amplitude), while those for $m=2$ (Figure 1c) are asymmetric. The combination of these two tidal components in the model, it turns out, is completely consistent with the above UARS observations.

It goes beyond the scope of this paper to provide a thorough understanding of the results presented here, which will require a great deal of analysis not yet carried out. Instead we discuss here the results from a modeling study that does provide some basic insight.

In Figure 2 we present the computed meridional wind amplitudes at $100 \mathrm{~km}$ for the first model year, delineating the total (a) or combined (eastward and westward) tide, and its westward (b) and eastward (c) components. This reveals the characteristic semiannual variation with maxima near equinox, which requires some time to develop but becomes fully developed during the second half of the year. As was evident in our earlier model results (Mayr et al., 2001a) for the combined tide (a), the large amplitude modulations indicate that they are caused by planetary wave (PW) interaction. And the results shown here reveal that this PW modulation apparently affects the eastward propagating tide (c) primarily.

Addressing the relatively large $\mathrm{m}=0$ tide generated in the NSM, we present in Figure $3 \mathrm{a}$ the amplitude modulations (computed with a 3 day window) at $100 \mathrm{~km}$ for the first model year. This reveals temporal variations that resemble those for the eastward propagating tide (Figure 2c). After the initial increase to produce a peak at the time around 2 months, the amplitude decreases and then grows again to reach maxima around 
7 and 9 months. For comparison, we also present the computed $\mathrm{m}=1 \mathrm{PWs}$ at $100 \mathrm{~km}$ for the meridional (b) and zonal (c) winds, which again show a similar pattern. After the initial 2.5 months, the amplitudes decrease and then increase again to reach peak values between 6.5 and 9.5 months - suggesting that PW interactions cause the nonmigrating tides in the NSM.

That PWs indeed are the cause for the nonmigrating tides is seen from the results of a numerical experiment, in which we selectively turned off the solar heating for $\mathrm{m}=0 \mathrm{but}$ retained the excitation source for the migrating tides. In this case, apparently, the instabilities that generate the PWs do not develop as is seen from the small amplitudes in Figures $4 \mathrm{~b}$ and $4 \mathrm{c}$ after the initial start-up noise (note the differences in the scales relative to Figures $3 b$ and $3 c$ ). As a result, the $m=0$ tide (Figure $4 a$ ) is also small, especially during the second half of the model year and beyond that (not shown). As expected, the amplitudes for the westward propagating diurnal tide in this case (not shown) are similar to those in Figures 2. Consistent with the results for the $m=0$ tide in Figure 4, the eastward propagating component then is also negligibly small.

Finally, we present in Figure 5 contour plots of the amplitudes for the computed meridional winds and temperature perturbations of the diurnal $\mathrm{m}=0$ tide at $100 \mathrm{~km}$. As seen also from Figure 1, the meridional winds (a) for this tidal component peak at the equator. Consistent with the resulting energy redistribution, the temperature perturbations (b) tend to straddle the wind field in both hemispheres, in particular during the months 15 and 20 near equinox when the wind amplitudes are largest.

\section{Discussion and Conclusion}

We have shown here for the fundamental diurnal tide that nonmigrating tides, having relatively large amplitudes, are generated in the NSM at altitudes above $80 \mathrm{~km}$. The evidence presented indicates that the nonmigrating tides are caused by nonlinear interactions between the migrating tide and the PWs, the latter generated through instabilities. Nonlinear interactions between long period planetary waves for $\mathrm{m}=1$, $\exp (i \Omega t \pm i \varphi)$, and the westward propagating tide, $\exp (i \omega t+i \varphi)$, would yield with 
$\Omega \ll \omega$ approximately $\approx \exp (i \omega t)$ for $m=0$, and $\approx \exp (i \omega t+2 i \varphi)$ for $m=2$, each modulated by the PW. We have seen from Figures 3 and 4 that this indeed appears to be the explanation for the $\mathrm{m}=0$ nonmigrating tide. It is also consistent with the results shown in Figure 1c for the westward propagating $m=2$ tide with a period of one day $(\omega)$, which is relatively large as was pointed out earlier.

The NSM solves the nonlinear Navier Stokes equations and thus, in principle, can account for the above-discussed process. A number of nonlinear processes can come into play, foremost perhaps the adiabatic heating (p.div(V)) that contributes to the relationship between temperature and wind fields shown in Figure 5.

The NSM also accounts for GW processes and in particular for the filtering of GWs, which can produce nonlinear interactions as we had argued earlier (Mayr et al., 1999, 2001, 2002). Gravity wave filtering appears to be a natural candidate for generating nonlinear interactions between the QBO and SAO to produce inter-seasonal variations in the upper mesosphere, between the QBO and the AO (annual oscillation) to produce quasi-decadal oscillations, and between the diurnal and semidiurnal tides.

In the present case, upward propagating GWs may encounter a PW and amplify it (Mayr et al., 2001b). This amplification occurs at the expense of the GW momentum flux in one or the other direction, which in turn decreases the flux in one or the other direction. The GW flux, thus modified by the PWs, then encounters the tide and amplifies it (Mayr et al., 2001a). In this process, the PW modulation of the GWs is transferred to the tide, which represents a nonlinear interaction essentially. Preliminary results from numerical experiments indeed indicate that such an interaction can contribute significantly to generate the nonmigrating tides in our NSM. This process is likely to be less important at lower altitudes where the filtering would not cut as deeply into the momentum flux. But at higher altitudes, it should become increasingly more important as the remaining GW momentum flux gets depleted by absorption and the accompanying filtering. Apart from the fact that the tides and PWs tend to grow with altitude, the nonlinear process of GW filtering on its own thus may become increasingly more important at higher altitudes. All this combined may help to explain, in part, why the nonmigrating tides grow to such large amplitudes in the upper mesosphere as our model results show. 
Considering GW filtering, the above-discussed nonlinear interaction between tides and PWs would in fact be "non-local" in the sense that height integration is involved. Gravity wave filtering by PWs at one height level will affect the interaction with the tide at a higher altitude level, thus producing an accumulative effect higher up. This may in part explain why our model results do not reveal, at a given altitude, a clear-cut correlation between the variable PWs and nonmigrating tides.

Acknowledgment: This work was performed in support of the TIMED project sponsored by NASA. Dr. Talaat's effort was supported under contract NAS5-97179 to the Johns Hopkins University, Applied Physics Laboratory.

\section{References}

Akmaev, R. A., Simulation of large-scale dynamics in the mesosphere and lower thermosphere with the Doppler-spread parameterization of gravity waves: 2 . Eddy mixing and the diurnal tide, J. Geophys. Res., 106, 1205, 2001 a

Akmaev, R. A., Simulation of large-scale dynamics in the mesosphere and lower thermosphere with the Doppler-spread parameterization of gravity waves: 1 . Implementation and zonal mean climatologies, J. Geophys. Res., 106, 1193, 2001b

Avery, S. K., R. A. Vincent, A. Phillips, A. H. Manson, and G. R. Fraser, High latitude tidal behavior in the mesosphere and lower thermosphere, J. Atm. Terr. Phys., 51, 595, 1989

Burrage M. D., M. E. Hagan, W. R. Skinner, D. L. Wu, and P. B. Hays, Long-term variability in the solar diurnal tide observed by HRDI and simulated by the GSWM, Geophys. Res. Lett., 22, 2641, 1995a

Burrage M. D., D. L. Wu, W. R. Skinner, D. A. Ortland, and P. B. Hays, Latitude and seasonal dependence of the semidiurnal tide observed by the high-resolution Doppler imager, J. Geophys. Res., 100, 11313, 1995b

Chan, K. L., H. G. Mayr, J. G. Mengel, and I. Harris, A 'stratified' spectral model for stable and convective atmospheres, J. Comp. Phys., 113, 165, 1994 
Ekanayake, E. M. T. Aso, and S. Miyahara, Background wind effect on propagation of nonmigrating diurnal tides in the middle atmosphere, J. Atmos. Terr. Phys., 59, 401, 1997

Forbes, J. M., and H. B. Garrett, Thermal excitation of atmospheric tides due to insolation absorption by $\mathrm{O}_{3}$ and $\mathrm{H}_{2} \mathrm{O}$, Geophys. Res. Lett., 5, 1013, 1978

Forbes, J. M., Tidal and planetary waves, Geophysical Monograph 87, 67, 1995

Fritts, D. C., Gravity wave-tidal interactions in the middle atmosphere: observations and theory, Geophysical Monograph 87, 89, 1995a

Fritts, D. C., Gravity wave forcing and effects in the mesosphere and lower thermosphere, Geophysical Monograph 87, 121, 1995b

Geller, M. A., V. A. Yudin, B. V. Khattatov, and M. E. Hagan, Modeling the diurnal tide with dissipation derived from UARS/HRDI measurements, Ann. Geophys., 15, 1198, 1997

Hagan, M. E., J. L. Chang, and S. K. Avery, Global-scale wave model estimates of nonmigrating tidal effects, J. Geophys. Res., 102, 163493, 1997

Hagan, M. E. and R. G. Roble, Modeling diurnal tidal variability with the National Center for Atmospheric Research thermosphere-ionosphere-mesosphereelectrodynamics general circulation model, J. Geophys. Res., 106, 24,869-24,882, 2001

Hays, P. B., D. L. Wu, and the HRDI science team, Observations of the diumal tide from space, J. Atmos. Sci., 51, 3077, 1994

Hines, C. O., Doppler-spread parameterization of gravity-wave momentum deposition in the middle atmosphere, 1, Basic formulation, J. Atmos. Solar Terr. Phys., 59, 371, $1997 \mathrm{a}$

Hines, C. O., Doppler-spread parameterization of gravity-wave momentum deposition in the middle atmosphere, 2, Broad and quasi monochromatic spectra, and implementation, J. Atmos. Solar Terr. Phys., 59, 387, 1997b

Khattatov, B. V., et al., Dynamics of the mesosphere and lower thermosphere as seen by MF radars and by the High Resolution Doppler Imager/UARS. J. Geophys. Res., 101, $10393-10404,1996$ 
Lieberman, R., Nonmigrating diurnal tides in the equatorial middle atmosphere, J. Atmos. Sci., 48, 1112, 1991

Manson, A. H., C. E. Meek, H. Teitelbaum, F. Vial, R. Schminder, D. Kuerschner, M. J. Smith, G. J. Fraser, and R. R. Clark, Climatology of semidiurnal and diurnal tides in the middle atmosphere (70-110 km) at middle latitudes (40-550), J. Atm. Terr. Phys., 51, 579, 1989

Mancini, E., N. A. McFarlane, and C. McLandress, Impact of the Doppler spread parameterization the simulation of the middle atmosphere circulation using the MA/ECHAM4 general circulation model, J. Geophys. Res., 102, 25,751, 1997

Mayr, H. G., J. G. Mengel, K. L. Chan, and H. S. Porter, Mesosphere dynamics with gravity forcing: Part I, Diurnal and semidiurnal tides, J. Atm. Solar-Terr. Phys., B, 1851,2001 a

Mayr, H. G., J. G. Mengel, K. L. Chan, and H. S. Porter, Mesosphere dynamics with gravity forcing: Part II, Planetary waves, J. Atm. Solar-Terr. Phys., 63, 1865, 2001b

Mayr, H. G., J. G. Mengel, K. L. Chan, and H. S. Porter, Seasonal variations of the diurnal tide induced by gravity wave filtering, Geophys. Res. Lett., 25, 943, 1998

McLandress, C., G. G. Shepherd, and B. H. Solheim, Satellite observations of thermospheric tides: Results from the Wind Imaging Interferometer on UARS, $J$. Geophys. Res., 101, 4093, 1996

McLandress, C., Sensitivity studies using the Hines and Fritts gravity wave drag parameterization, NATO ASI Series, 50, 45, 1997

Mengel, J. G., Mayr, H. G., Chan, K. L., Hines, C. O., Reddy, C. A., Arnold, N. F., Porter, H. S., 1995. Equatorial oscillations in the middle atmosphere generated by small-scale gravity waves, Geophys. Res. Lett., 22 , 3027

Miyahara, S., Y, Miyoshi, and K. Yamashita, Variations of migrating and nonmigrating atmospheric tides simulated by a middle atmosphere general circulation model, $A d v$. Space Res., 24(11), 1549-1558, 1999.

Miyahara, S, Y. Toshida, and Y. Miyoshi, Dynamical coupling between the lower and upper atmosphere by tides and gravity waves, J. Atm. Terr. Phys., 55, 1039, 1993

Strobel, D. F., Parameterization of atmospheric heating rate from 15 to $120 \mathrm{~km}$ due to $\mathrm{O} 2$ and O3 absorption of solar radiation, J. Geophys. Res., 83, 7963, 1978 
Talaat, E. R., and R. Lieberman, Nonmigrating diurnal tides in mesospheric and lower thermospheric winds and temperatures J. Atmos. Sci., 56, 4073, 1999

Teitelbaum, $\mathrm{H}$. and F. Vial, On tidal variability induced by nonlinear interaction with planetary waves, J. Geophys. Res., 96, 14,169-14,178, 1991

Teitelbaum, H., F. Vial, A. H. Manson, R. Giraldez, and M. Massebeuf, Nonlinear interaction between the diurnal and semidiurnal tides: Terdiurnal and diurnal secondary waves, J. Atm. Terr. Phys., 51, 627, 1989

Walterscheid, R. L., G. G. Sivjee. G. Schubert, and R. M. Hamwey, Large amplitude semidiumal temperature variations in the polar mesopause: evidence of pseudotide, Nature, 324, 1986

Vincent, R. A., T. Tsuda, and S. Kato, Asymmetries in mesospheric tidal structure, $J$. Atm. Terr. Phys., 51, 609, 1989

Yudin, V. A., B. V. Khattatov, M. A. Geller, et al.. Thermal tides and studies to tune the mechanistic tidal model using UARS observations, Ann. Geophys., 15, 1205, 1997

\section{Figure Captions}

Figure 1: Generated with the classical westward migrating excitation sources only, amplitudes are presented of meridional winds for the eastward (solid lines) and westward (dashed) propagating tides with zonal wave numbers $m=0$ to 2 and period of 1 day (24 hours), which are computed for a short time span near solstice (24 to 26 months) with the Sun in the southern hemisphere. To eliminate cluttering, the contours are truncated below $50 \%$, and the maximum wind velocities are recorded in each panel.

Figure 2: Computed amplitudes of the zonal wave number $\mathrm{m}=1$ diurnal tide at $100 \mathrm{~km}$ altitude for the first model year, delineating the total (a) or combined tide (eastward and westward), and its westward (b) and eastward (c) components. Note the large planetary wave (PW) modulation of the eastward component (c), which appears also in the combined tidal oscillation (a) but not in the westward component (b). 
Figure 3: Temporal variations for the amplitudes of the $m=0$ tide during the first model year at $100 \mathrm{~km} \mathrm{(a),} \mathrm{and} \mathrm{the} \mathrm{computed} \mathrm{meridional} \mathrm{(b)} \mathrm{and} \mathrm{zonal} \mathrm{(c)} \mathrm{winds} \mathrm{of} \mathrm{the} \mathrm{m}=1$ PWs at this altitude. Note the correlations between the temporal variations of the PW amplitudes (b, c) and the $\mathrm{m}=0$ tide (a) as well as the eastward tide (Figure $1 \mathrm{c}$ ), in particular during the first 6 months.

Figure 4: Same as Figure 3 but without the $m=0$ heat source. Note the small PW amplitudes for $m=1$ (with scales different from those in Figure 3) and the corresponding small $\mathrm{m}=0$ tide. After the start-up noise during the first half model year, the PWs and tide drastically decrease to attain small values that continue to remain small beyond the first model year.

Figure 5: Contour plots of computed amplitudes for the meridional winds and temperature perturbations at $100 \mathrm{~km}$ for the $\mathrm{m}=0$ diurnal tide. The contours below the $40 \%$ level were suppressed to reveal more clearly the patterns in the seasonal variations. 

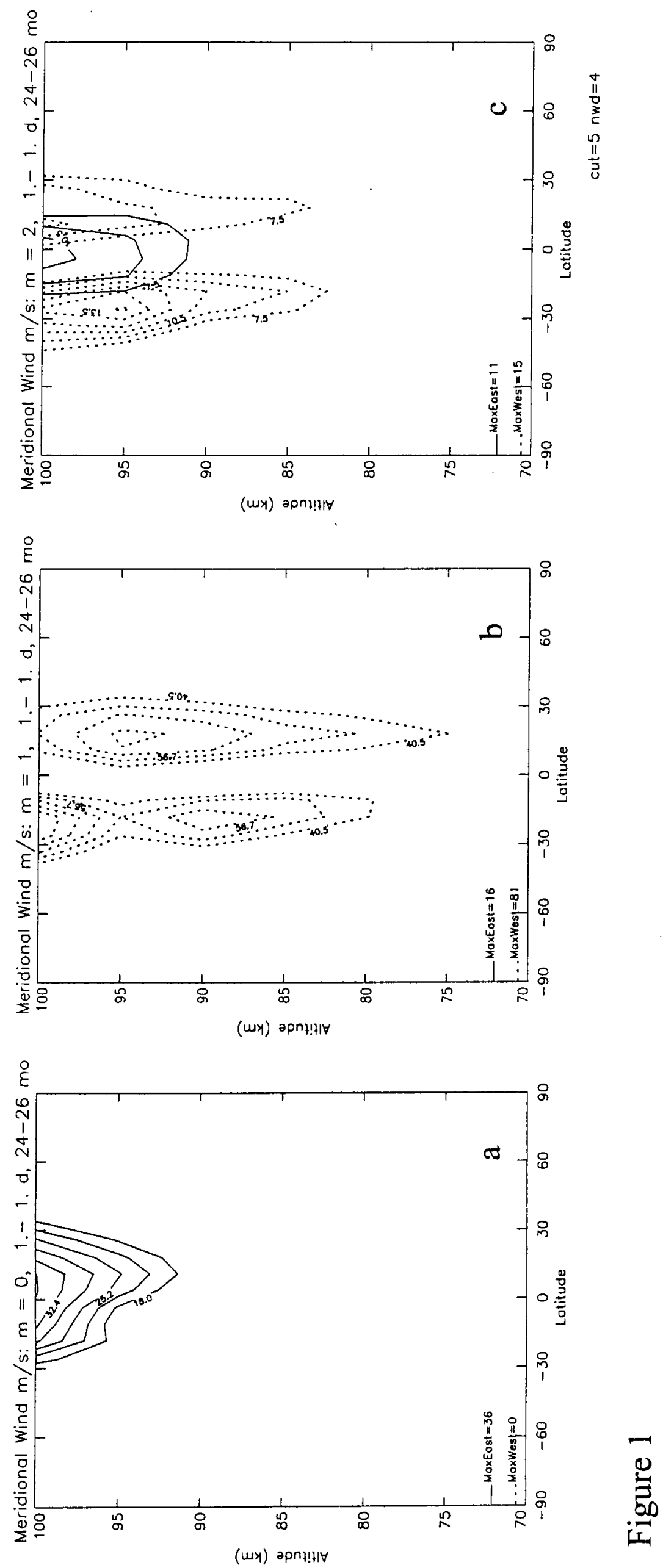


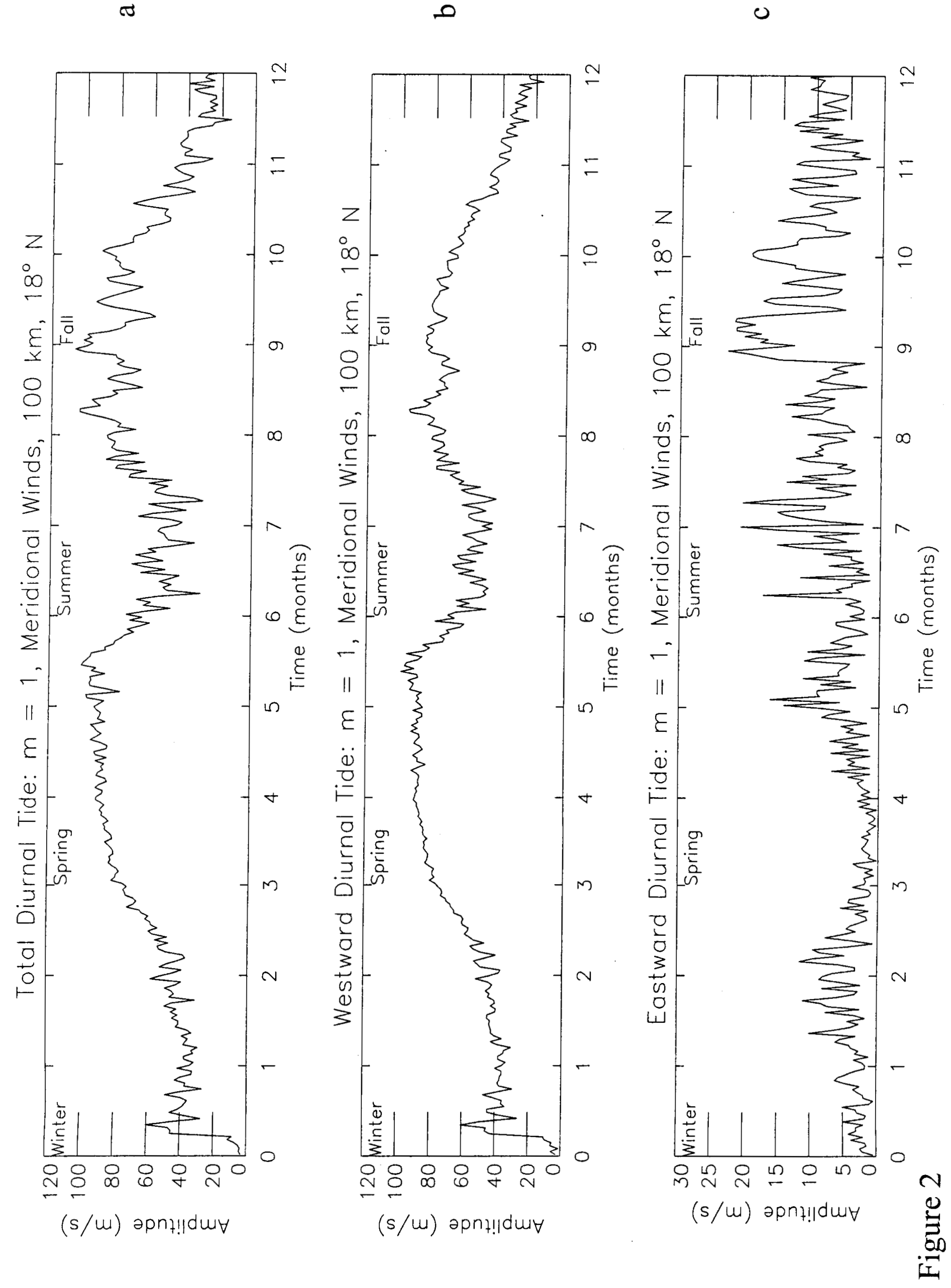




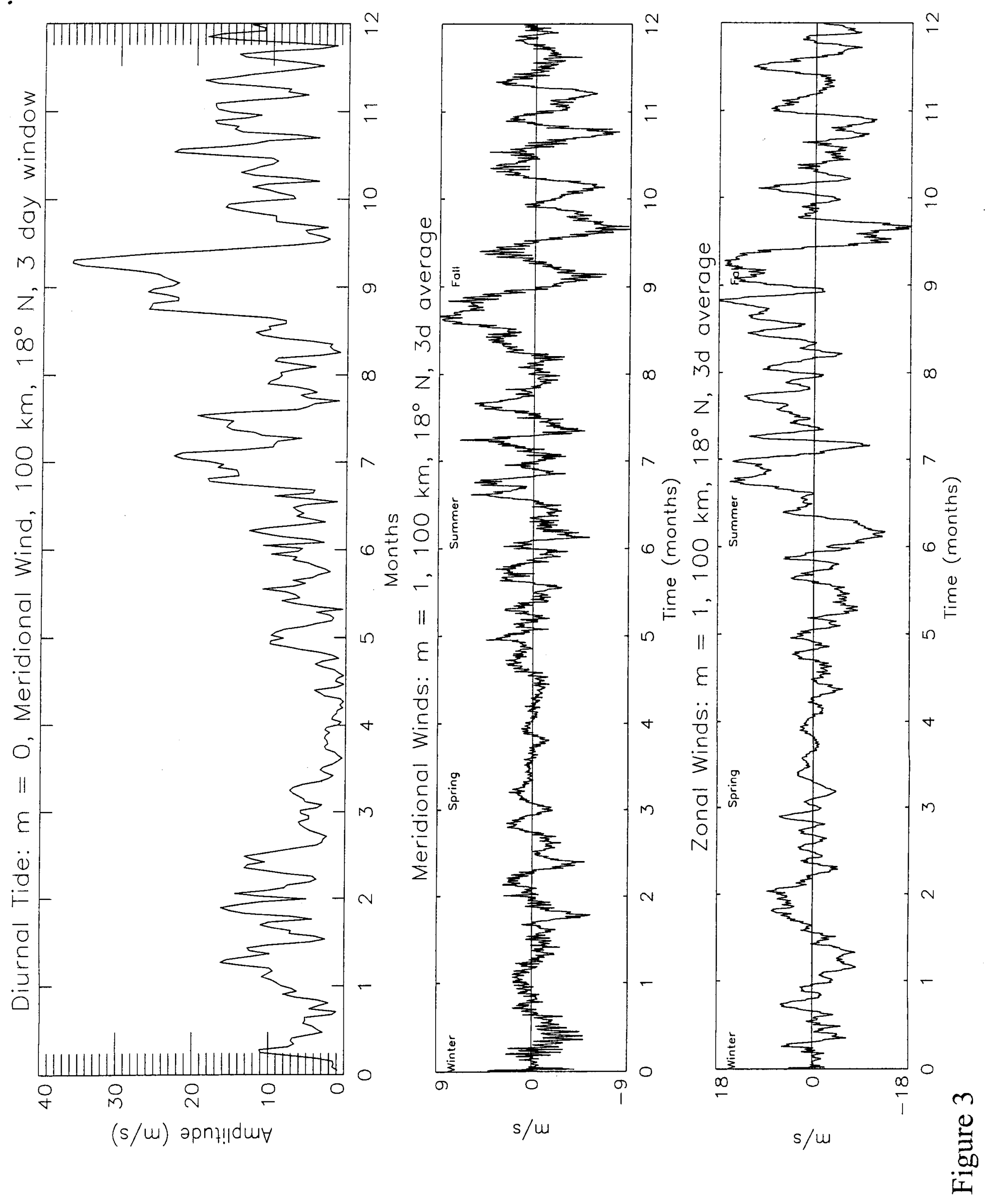




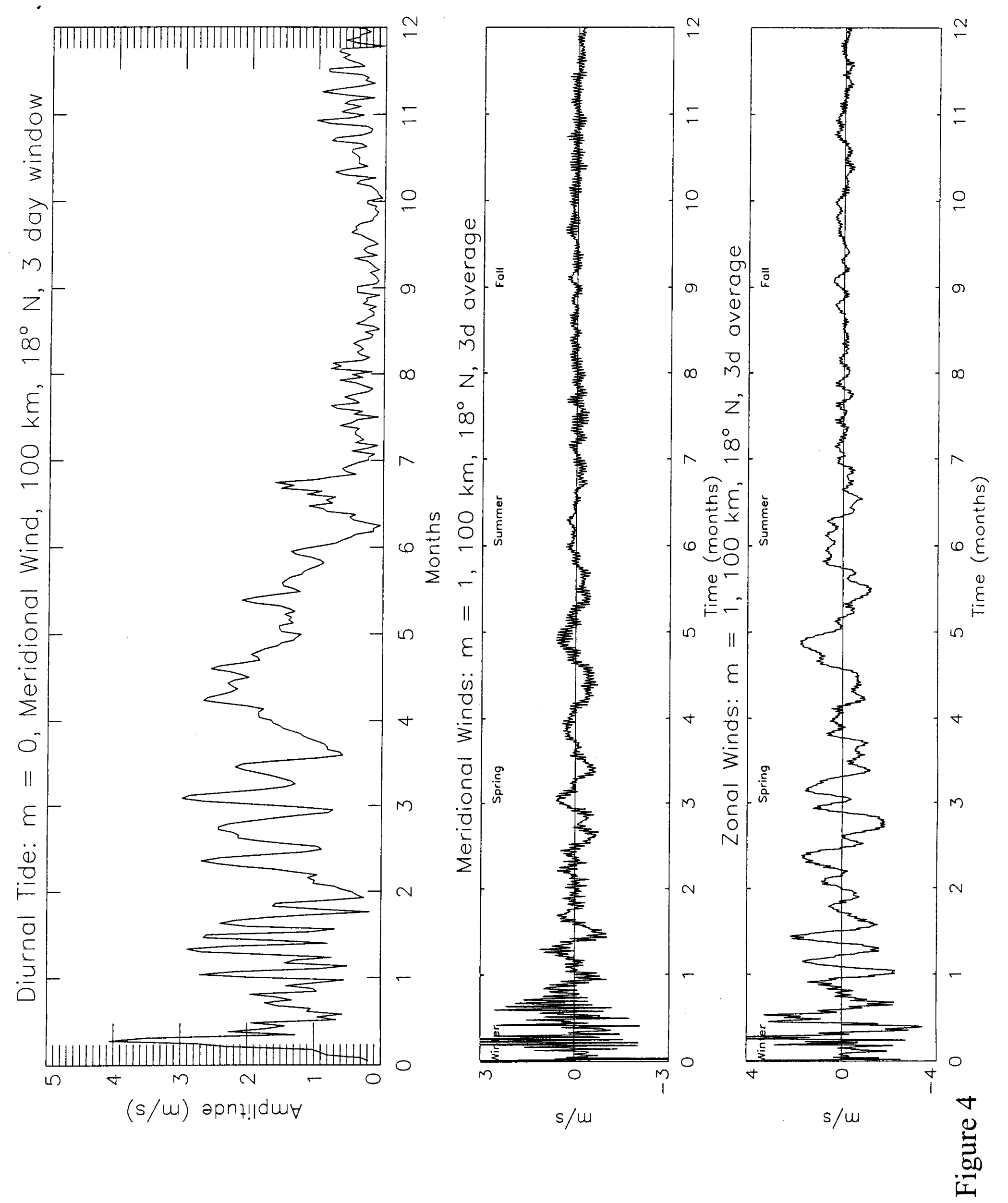



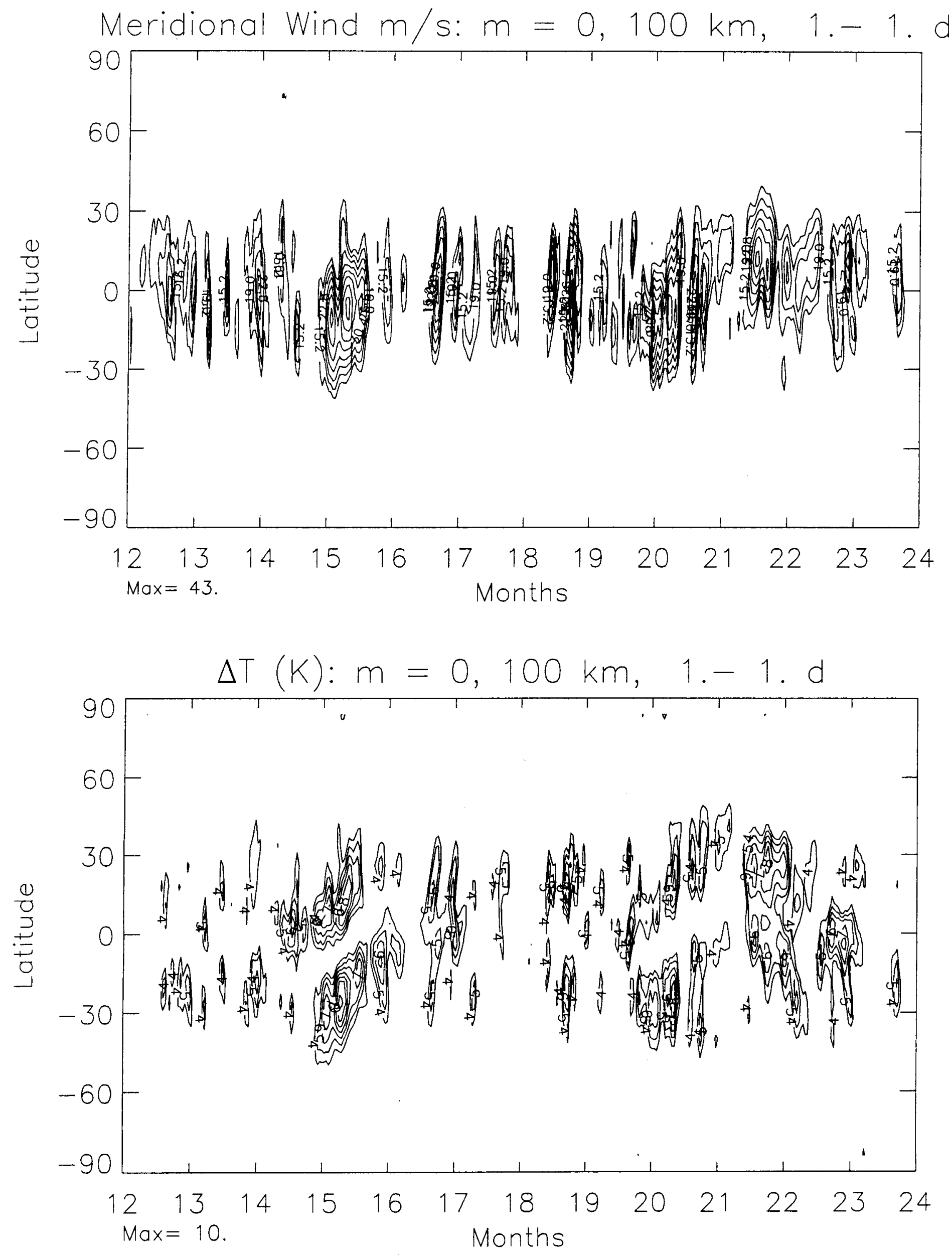

Figure 5 